\title{
PENGUKURAN TINGKAT KAPABILITAS MANAJEMEN RISIKO SISTEM INFORMASI KOPERASI SYARIAH MENGGUNAKAN FRAMEWORK COBIT 5
}

\author{
Arief ichwani $^{1}$, Astrina Dewi Farida ${ }^{2}$ \\ Sistem Informasi, Fakultas Ilmu Komputer, Universitas Esa Enggul, \\ Jalan Arjuna Utara No.9 Kebon Jeruk Jakarta 11510 Jakarta 11510 \\ Telp. (021) 5674223 \\ arief.ichwani@esaunggul.ac.id ${ }^{1}$, astrinadf@gmail.com ${ }^{2}$
}

\begin{abstract}
The application of IT offers many benefits in the company's business processes. Such as contribute to added value, excellent service, effective and efficient business operations. In addition to providing various benefits for business development, IT also has risk that must be managed optimally. This study aims to measure the level of risk management capabilities of the Syariah Cooperative Information System at KSPPS XYZ, the target level of capability and make a contribution to improvement. Measurement of the level of capability in risk management is done by using COBIT 5 domains EDM03 (Ensure Risk Optimisation) and APO12 (Manage Risk). Based on the measurements that have been made, domains EDM03 and APO12 capability levels are currently at level 0 (incomplete), while domains EDM03 and APO12 capability targets are level 3 (established). To achieve the capability level target, risk management approval is proposed for the KSPPS XYZ Syariah Cooperative Information System.
\end{abstract}

Keywords: APO12, COBIT 5, EDM03, Risk Management.

\section{PENDAHULUAN}

Koperasi Simpan Pinjam Pembiayaan Syariah (KSPPS) XYZ merupakan salah satu koperasi di Tangerang yang menggunakan Teknologi Informasi (TI) untuk mendukung peningkatan kualitas guna menunjang kinerja organisasi. Hal tersebut terlihat dari penggunaan Sistem Informasi Koperasi Syariah KSPPS XYZ. TI membutuhkan peralatan pendukung seperti jaringan, hardware dan software yang jumlahnya tak sedikit. Peralatan pendukung tersebut merupakan aset yang bernilai nyata, disamping itu terdapat aset dengan nilai yang tak terwujud seperti ketika suatu fungsi dari sistem terhenti hal tersebut akan mengakibatkan terganggunya proses kerja yang menjadi tidak optimal dan dapat mengakibatkan turunnya kualitas organisasi. Tak dapat dipungkiri, setiap aktivitas yang dilakukan pasti mengandung risiko, termasuk TI. Risiko adalah variasi dalam hal-hal yang mungkin terjadi secara alami, atau peristiwa yang tidak terduga yang dapat menyebabkan kerugian finansial [1]. Jika risiko TI tidak dikelola dengan benar, maka TI juga dapat berkontribusi terhadap kegagalan perusahaan [2].

Tata kelola TI adalah proses dimana tujuan entitas yang memberikan dampak pada teknologi informasi disepakati, diarahkan, dan dikendalikan. Tujuan utama tata kelola TI adalah untuk mengurangi risiko dan memastikan bahwa investasi dalam sumber daya TI menambah nilai bagi perusahaan [3]. Pengelolaan risiko TI menjadi elemen kunci dalam tata kelola organisasi agar optimasi risiko dapat dilakukan, untuk mengidentifikasi kerentanan dan memberikan rekomendasi [2], maka diperlukan pengukuran tingkat kapabilitas sehingga rekomendasi perbaikan dapat diberikan untuk mencapai target kapabilitas yang diinginkan oleh perusahaan.

Dalam implementasi pengukuran kapabilitas diperlukan kerangka kerja (framework), framework yang akan digunakan adalah COBIT 5 karena telah mengintegrasikan semua pengetahuan yang sebelumnya tersebar di berbagai framework yang berbeda. COBIT 5 menyatukan panduan ISACA yang ada yaitu COBIT 4.1, Val IT 2.0, Risk IT, dan BMIS [4]. Selain itu COBIT 5 juga menyesuaikan antara best practices yang ada seperti 
ITIL V3, TOGAF dan ISO. COBIT 5 mencakup lima domain dengan 37 proses dan secara jelas memberikan batasan perbedaan antara governance dan management. Ada satu domain pada area governance yaitu Evaluate, Direct and Monitor (EDM) dan empat proses pada area Management yaitu Align, Plan and Organize (APO); Build, Acquire and Implement (BAI); Deliver, Service and Support (DSS) dan Monitor, Evaluate and Assess (MEA). Pengelolaan risiko pada framework COBIT 5 tedapat pada subdomain EDM03 dan APO12. Subdomain EDM03 yang terletak pada area Governance memastikan bahwa ada optimasi risiko. Tiga proses utama pada subdomain EDM03 yaitu melakukan evaluasi terhadap implementasi manajemen risiko, memberikan arahan kepada management untuk mengelola risiko, dan melakukan pengawasan untuk memastikan bahwa manajemen risiko telah dijalankan secara efektif. Sedangkan subdomain APO12 terdapat pada area Management yang berfungsi untuk mengelola risiko. APO1 2 memiliki 6 proses yaitu mengumpulkan data yang relevan mengenai risiko, menganalisa risiko tersebut untuk memperhitungkan relevansi bisnis dari faktor risiko, mengelolanya menjadi risk profile, memilah risiko mana yang bisa dihindari atau risiko mana yang harus dimitigasi, mengelola peluang untuk mengurangi risiko, dan menyiapkan rencana untuk menanggapi risiko.

\section{Landasan Teori}

\subsection{Tata Kelola Teknologi Informasi}

Tata kelola TI memiliki definisi inklusif yang mencakup sistem informasi (SI), teknologi dan komunikasi, bisnis dan hukum serta isu-isu lain yang melibatkan hampir seluruh pemangku kepentingan (stakeholder), baik direktur, manajemen eksekutif, pemilik proses, supplier, pengguna TI bahkan pengaudit SI/TI. Pembentukan dan penyusunan tata kelola tersebut merupakan tanggung jawab dari jajaran direksi dan manajemen eksekutif [5].

Tata Kelola TI dibedakan menjadi 5 fokus area utama, yaitu [6]:

1. Penyelarasan Strategis (Strategic Alignment)

2. Penyampaian Nilai (Value Delivery)

3. Pengelolaan Risiko (Risk Management)

4. Pengelolaan Sumber Daya (Resource Management)

5. Pengukuran Kinerja (Performance Management)

Tiga pilar dari IT Governance [7]:

1. Manajemen Infrastruktur Teknologi Informasi

2. Pengelolaan terhadap penggunaan/permintaan terhadap layanan IT

3. Manajemen Proyek teknologi Informasi

Gartner mendefinisikan tata kelola TI sebagai serangkaian proses yang memastikan penggunaan TI yang efektif dan efisien yang memungkinkan organisasi untuk mencapai tujuannya [3].

\subsection{Manajemen Risiko Teknologi Informasi}

Manajemen risiko Teknologi Informasi (TI) merupakan gabungan beberapa proses yang terdiri dari identifikasi, pengkajian, pengembangan stategi mitigasi dan komunikasi risiko TI yang berpotensi menimbulkan dampak negatif dan dapat merugikan organisasi [8].

Sebagaimana risiko TI merupakan risiko pada organisasi yang disebabkan oleh penggunan TI dalam suatu organisasi, terdiri dari semua kejadian yang terkait dengan penggunaan TI dan memiliki potensi yang berdampak pada organisasi [9].

Manajemen risiko mencakup beberapa elemen [2]:

1. penilaian risiko. Manajemen risiko dimulai dengan penilaian risiko atau analisis risiko. Ada beberapa langkah untuk penilaian risiko:

a. identifikasi aset TI organisasi dan nilainya. Mencakup data, perangkat keras, perangkat lunak, layanan, dan infrastruktur TI.

b. identifikasi ancaman dan kerentanan terhadap aset. Prioritaskan ancaman dan kerentanan.

c. identifikasi kemungkinan kerentanan akan dieksploitasi oleh ancaman. Ini adalah risiko.

d. identifikasi dampak risiko. Risiko dengan dampak yang lebih tinggi harus ditangani terlebih dahulu. 
2. mengidentifikasi risiko untuk dikelola. Dapat memilih untuk menghindari, mentransfer, memitigasi, atau menerima risiko. Keputusan sering didasarkan pada kemungkinan risiko yang terjadi, dan dampak yang akan terjadi jika itu terjadi.

3. pemilihan kontrol. Setelah mengidentifikasi risiko apa yang harus ditangani, metode kontrol dapat diidentifikasi dan dipilih. Metode kontrol juga disebut sebagai tindakan balasan. Kontrol terutama difokuskan pada pengurangan kerentanan dan dampak.

4. implementasi dan pengujian kontrol. Setelah diterapkan, kontrol dapat diuji untuk memastikan mereka memberikan perlindungan yang diharapkan.

5. evaluasi kontrol. Manajemen risiko adalah proses yang berkelanjutan. Kontrol yang diimplementasikan harus dievaluasi secara teratur untuk menentukan apakah mereka masih memberikan perlindungan yang diharapkan. Evaluasi sering dilakukan dengan melakukan penilaian kerentanan rutin.

\subsection{Koperasi}

Menurut Undang-Undang Nomor 25 Tahun 1992 [10] definisi koperasi adalah badan usaha yang beranggotakan orang-seorang atau badan hukum koperasi dengan melandaskan kegiatannya berdasarkan prinsip koperasi sekaligus sebagai gerakan ekonomi rakyat yang berdasar atas asas kekeluargaan.

Dasar hukum koperasi antara lain [11]:

1. Undang-undang No.25 Tahun 1992 tentang Perkoperasian.cdd

2. Peraturan Pemerintah No. 4 Tahun 1994 tentang Persyaratan dan Tata Cara Pengesahan Akta Pendirian dan Perubahan Anggaran dasar Koperasi.

3. Peraturan Menteri No. 01 Tahun 2006 yaitu tentang Petunjuk Pelaksanaan Pembentukan, Pengesahan Akta Pendirian dan Perubahan Anggaran Dasar Koperasi.

\subsection{Control Objective for Information and related Technology 5 (COBIT 5)}

COBIT 5 merupakan sebuah kerangka kerja generasi terbaru dari panduan ISACA yang membahas mengenai tata kelola dan manajemen TI. COBIT 5 menyediakan kerangka kerja yang membantu perusahaan dalam mencapai tujuan mereka dengan tata kelola dan manajemen teknologi informasi [12]. COBIT 5 menyediakan framework yang komprehensif yang membantu perusahaan untuk mencapai tujuannya dalam melaksanakan tata kelola dan manajemen teknologi informasi. Dengan demikian, perusahaan dapat menciptakan nilai yang optimal dari teknologi informasi dengan menjaga keseimbangan antara mewujudkan manfaat, mengoptimalkan tingkat risiko dan penggunaan sumber daya. COBIT 5 memungkinkan teknologi informasi untuk diatur dan dikelola secara holistik untuk seluruh perusahaan dan memberikan gambaran yang jelas terkait keterlibatan stakeholders dalam tata kelola tersebut [13].

Model penilaian kapabilitas proses pada COBIT 5 berdasarkan pada ISO/IEC 15504, standar mengenai Software Engineering dan Process Assessment [14]. Model ini mengukur performansi tiap-tiap proses tata kelola (EDM-based) atau proses manajemen (PBRM-based), dan dapat mengidentifikasi area-area yang perlu untuk ditingkatkan performansinya. Kapabilitas proses merupakan karakteristik dari kemampuan sebuah proses untuk mencapai tujuan bisnis saat ini ataupun saat mendatang. Penilaian kapabilitas proses dilakukan untuk mengidentifikasi level kapabilitas proses tertentu dan kemudian menentukan langkah selanjutnya untuk melakukan peningkatan terhadap kapabilitas proses tersebut. Pengukuran kapabilitas akan didasarkan pada atribut proses (PA). Setiap atribut mendefinisikan aspek tertentu dari kapabilitas proses. Kombinasi pencapai atribut proses tersebut akan menentukan tingkat kapabilitas proses [14].

Ada enam level kapabilitas yang dapat dicapai suatu proses, termasuk 'incomplete process' jika praktik di dalamnya tidak mencapai tujuan proses yang dimaksud [4]:

1. 0 incomplete process: Proses tidak diimplementasikan atau gagal mencapai tujuan prosesnya.

2. 1 performed process: Proses yang diimplementasikan mencapai tujuan prosesnya.

3. 2 managed process: Proses yang dilakukan yang dijelaskan sebelumnya sekarang diimplementasikan dengan cara yang terkelola (terencana, dipantau dan disesuaikan) dan produk kerjanya dibuat dengan tepat, dikendalikan, dan dipelihara.

4. 3 established process: Proses terkelola yang dijelaskan sebelumnya sekarang diimplementasikan menggunakan proses yang ditentukan yang mampu mencapai hasil prosesnya. 
5. 4 predictable process: Proses yang ditetapkan sebelumnya dijelaskan sekarang beroperasi dalam batas yang ditentukan untuk mencapai hasil prosesnya.

6. 5 optimising process: Proses yang dapat diprediksi yang dijelaskan sebelumnya terus ditingkatkan untuk memenuhi sasaran bisnis saat ini dan yang diproyeksikan relevan.

Setiap tingkat kemampuan hanya dapat dicapai ketika tingkat di bawah ini telah sepenuhnya tercapai. Misalnya, kapabilitas proses level 3 (established process) membutuhkan definisi proses dan atribut penyebaran proses untuk sebagian besar dicapai, di atas pencapaian penuh atribut untuk kapabilitas proses level 2 (proses yang dikelola) [4]. Sedangkan skala rating atribut pada COBIT 5 yang digunakan untuk menilai, skala tersebut telah ditetapkan oleh ISO/IEC 15504. yaitu [13]:

1. Not achieved $(\mathrm{N})$, dengan nilai $0-15 \%$ pencapaian.

2. Partially achieved $(\mathrm{P})$, dengan nilai $>15 \%-50 \%$ pencapaian.

3. Largely achieved (L), dengan nilai $>50 \%-85 \%$ pencapaian.

4. Fully achieved (F), dengan nilai $>85 \%-100 \%$ pencapaian.

Keterlibatan stakeholders dalam pelaksanaan kegiatan-kegiatan yang terdapat pada proses diatur dalam Responsible Accountable Consulted Informed (RACI) chart. Berikut tingkat keterlibatan yang berbeda dari setiap stakeholders [13].

1. Responsible, yaitu stakeholders yang melaksanakan kegiatan. Pelaksanaan kegiatan haruslah dapat mencapai tujuan proses.

2. Accountable, yaitu stakeholders yang bertanggung jawab atas keberhasilan kegiatan secara keseluruhan dan memiliki otoritas untuk melakukan pengambilan keputusan.

3. Consulted, yaitu stakeholders yang diperlukan untuk memberikan masukan atau sarannya untuk pelaksanaan kegiatan pada proses.

4. Informed, yaitu stakeholders yang perlu mendapatkan pemberitahuan terkait pelaksanaan dan pencapaian kegiatan pada proses.

Menurut ISACA, COBIT 5 mempunyai dua proses yang membahas mengenai manajemen risiko Teknologi Informasi (TI), yaitu EDM03 dan APO12 [8].

1. EDM03 (Ensure Risk Optimisation)

Bertujuan untuk memastikan tingkat risiko dan besarnya toleransi yang dapat diterima perusahaan telah dipahami, diartikulasikan dan dikomunikasikan dengan baik, serta memastikan apakah risiko yang terkait dengan TI telah diidentifikasi dan dikelola dengan baik. Proses EDM03 terdiri dari EDM03.01 (Evaluate Risk Management), DM03.02 (Direct Risk Management) dan EDM03.03 (Monitor Risk Management)

2. APO12 (Manage Risk)

Bertujuan untuk mengidentifikasi, menilai dan mengurangi risiko terkait dengan TI agar tidak melebihi batas toleransi yang telah ditentukan organisasi. Dan mengintegrasikan manajamen risiko TI dengan manajemen risiko perusahaan (ERM). Proses ini terdiri dari APO12.01 (Collect Data), APO12.02 (Analyse Risk), APO12.03 (Maintain A Risk Profile), APO12.04 (Articulate Risk), APO12.05 (Define a Risk Management Action Portofolio) dan APO12.06 (Respond to Risk). 
Vol 8 No. 1 , 2020

(C)2020 Ilmu Komputer Unila Publishing Network All Rights Reserved

\section{Metode Penelitian}

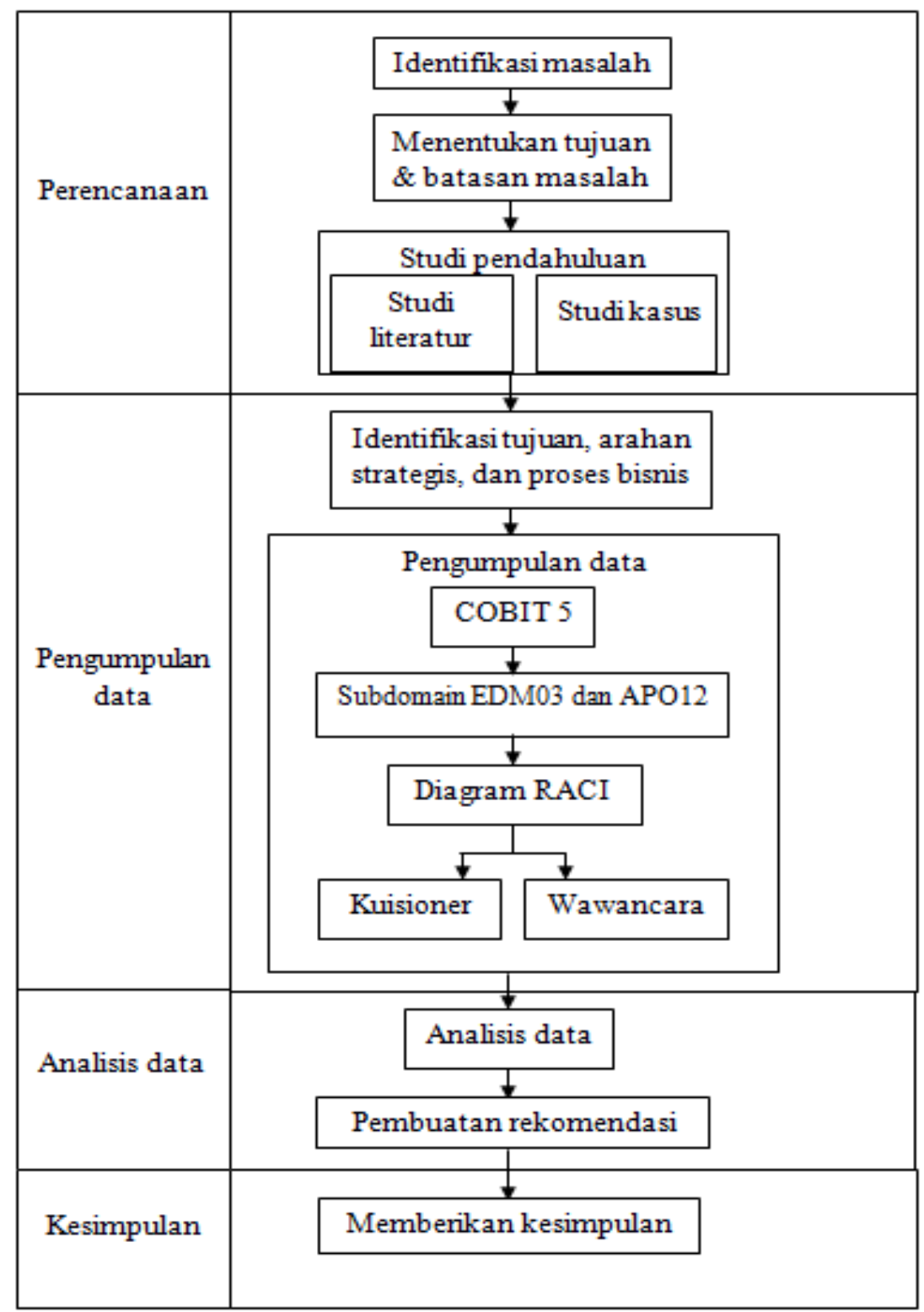

Gambar 1 Tahapan Penelitian

Gambar 1 merupakan rangkuman tahapan penelitian. Adapun penjelasannya adalah sebagai berikut:

1. tahapan pertama dalam proses pengukuran kapabilitas manajemen risiko teknologi informasi ini adalah melakukan identifikasi masalah dari latar belakang yang sudah dipaparkan.

2. menentukan tujuan dan batasan tugas akhir dari identifikasi masalah yang telah ditentukan sebelumnya.

3. melakukan studi mengenai tata kelola teknologi informasi, sistem informasi koperasi syariah KSPPS XYZ, manajemen risiko teknologi informasi, COBIT 5 dan penelitian terdahulu yang terkait dengan manajemen risiko teknologi informasi. 
4. mengidentifikasi tujuan, arahan strategis, dan proses bisnis KSPPS XYZ mengenai manajemen risiko sistem informasi koperasi syariah.

5. melakukan pengumpulan data dengan metode wawancara dan kuesioner kepada responden yang terlibat dalam proses manajemen risiko teknologi informasi. Penentuan responden dilakukan berdasarkan diagram RACI subdomain EMD03 dan APO12 yang disesuaikan dengan struktur organisasi KSPPS XYZ. Pada tahap ini juga ditentukan target kapabilitas yang ingin dicapai.

6. melakukan analisa data dengan metode kualitatif sesuai standart penilaian pada COBIT 5 hingga menghasilkan capability level.

7. membuat rekomendasi pengelolaan risiko sistem informasi koperasi syariah KSPPS XYZ agar target kapabilitas dapat tercapai.

8. membuat kesimpulan dari penelitian.

\section{Hasil dan Pembahasan}

\subsection{Target Level Kapabilitas}

Target kapabilitas optimasi risiko dan manajemen risiko sistem informasi koperasi syariah ditentukan dengan metode wawancara yang dilakukan dengan para stakeholder terkait optimasi risiko dan manajemen risiko. Berdasarkan wawancara dengan staff IT, manajer SDI dan maal serta manajer operasional, didapatkan informasi target level kapabilitas yang dirangkum dalam Tabel 1.

Tabel 1 Target Level Kapabilitas

\begin{tabular}{ccccc}
\multirow{2}{*}{ Proses } & \multicolumn{3}{c}{ Responden } & \multirow{2}{*}{ Hasil } \\
\cline { 2 - 4 } & 1 & 2 & 3 & \\
\hline EDM03 (Ensure Risk Optimisation) & 3 & 2 & 5 & 3 \\
APO12 (Manage Risk) & 3 & 2 & 5 & 3
\end{tabular}

Dari Tabel 1 diketahui bahwa target kapabilitas proses optimasi risiko dan manajemen risiko berada pada level 3. Untuk mencapai level tersebut, rating ketercapaian atribut yang harus dicapai sistem informasi koperasi syariah KSPPS XYZ pada proses optimasi risiko dan manajemen risiko ialah fully achieved untuk level 1 sampai 2 serta largely achieved untuk level 3. Hal ini menunjukkan bahwa proses optimasi risiko dan manajemen risiko baku dan terstandarisasi.

\subsection{Penentuan Responden}

Penentuan responden yang terlibat dalam pengukuran kapabilitas manajemen risiko teknologi informasi didasarkan pada tabel RACI (Responsible, Accountable, Consulted and Informed) subdomain EDM03 dan APO12 pada COBIT 5 serta struktur organisasi KSPPS XYZ. Tabel RACI menggambarkan keterlibatan stakeholders dalam proses manajemen risiko sistem informasi koperasi syariah KSPPS XYZ. Tabel 2 menggambarkan responden penelitian pada subdomain EDM03 (Ensure Risk Optimisation), sedangkan Tabel 3 menggambarkan responden penelitian pada subdomain APO12 (Manage Risk).

Tabel 2 Responden Penelitian Subdomain EDM03

\begin{tabular}{ll}
\hline \multicolumn{1}{c}{ RACI pada COBIT 5 } & \multicolumn{1}{c}{ Pihak KSPPS XYZ yang mewakili } \\
\hline Chief Executive Officer & Pengurus \\
\hline Chief Financial Officer & $\begin{array}{l}\text { Manajer keuangan, Bagian pembukuan dan } \\
\text { akuntansi, Bagian kelembagaan dan pendanaan }\end{array}$ \\
\hline Chief Operating Officer & General manager \\
\hline Project Management Office & Manager operasional dan Manager cabang \\
\hline
\end{tabular}




\begin{tabular}{ll}
\hline Value Management Office & Bagian kepegawaian, Bagian ZIS Waf \\
\hline Chief Risk Officer & Bagian teknologi informasi \\
\hline Chief Information Security Officer & Bagian teknologi informasi \\
\hline Head Human Resources & Manajer SDI dan Maal \\
\hline \multicolumn{1}{c}{ RACI pada COBIT 5 } & Pihak KSPPS XYZ yang mewakili \\
\hline Compliance & Pengawas dan SPI \\
\hline Chief Information Officer & Bagian teknologi informasi \\
\hline Service Manager & Bagian layanan anggota \\
\hline
\end{tabular}

Tabel 3 Responden Penelitian Subdomain APO12

\begin{tabular}{ll}
\hline \multicolumn{1}{c}{ RACI pada COBIT 5 } & \multicolumn{1}{c}{ Pihak KSPPS XYZ yang mewakili } \\
\hline Chief Executive Officer & Pengurus \\
\hline Project Management Office & Manager operasional dan Manager cabang \\
\hline Chief Risk Officer & Bagian teknologi informasi \\
\hline Chief Information Security & Bagian teknologi informasi \\
\hline Officer & Pengawas dan SPI \\
\hline Chief Information Officer & Bagian teknologi informasi \\
\hline Service Manager & Bagian layanan anggota \\
\hline
\end{tabular}

\subsection{Pembahasan Hasil Penelitian}

Dari 19 orang responden EDM03 dan 12 orang responden APO12 yang diberikan kuesioner tahap 1 dan 2, hanya 5 orang yang mengembalikan kuesioner EDM03 (Ensure Risk Optimisation) dan APO12 (Manage Risk) yaitu manajer keuangan, manajer operasional, manajer SDI dan maal, dan dua staff IT. Ke-14 responden EDM03 (Ensure Risk Optimisation) dan ke-7 responden APO12 (Manage Risk) tidak mengembalikan kuesioner karena berbagai alasan. Namun, jawaban dari responden yang mengembalikan kuesioner cukup mampu menggambarkan kondisi sistem informasi koperasi syariah KSPPS XYZ karena sebagian besar responden tersebut yang menangani risiko TI pada KSPPS XYZ.

Dari 5 orang responden EDM03 (Ensure Risk Optimisation) dan APO12 (Manage Risk), hanya 3 orang responden yang berhasil diwawancarai, yaitu staff IT, manajer SDI dan maal serta manajer operasional. Responden lainnya tidak bisa diwawancarai karena ketidakcocokan dan keterbatasan waktu antara penulis dan responden. Namun jawaban dari ketiga responden yang diwawancara dianggap sudah cukup merepresentasikan realita yang terjadi pada sistem informasi koperasi syariah KSPPS XYZ karena yang menangani risiko TI pada KSPPS XYZ adalah ketiga responden tersebut.

Setelah dilakukan wawancara untuk validasi dan verifikasi dokumen, selanjutnya dilakukan pengukuran ketercapaian atribut proses berdasarkan data yang ada. Ketercapaian level 1 kapabilitas didasarkan pada jawaban "Ya" yang telah divalidasi dengan hasil verifikasi dokumen. Persentase jawaban "Ya" menunjukkan sejauh mana base practices dan work products dalam optimasi risiko dan manajemen risiko sistem informasi koperasi syariah KSPPS XYZ dilaksanakan. Jumlah persentase tersebut selanjutnya dihubungkan dengan skala rating atribut proses COBIT 5. Level 1 tercapai apabila rating atribut mencapai largely achieved dengan jumlah persentase sebesar $>50-85 \%$ atau mencapai fully achieved dengan jumlah persentase $>85-100 \%$. 
Sedangkan ketercapaian level 2-5 kapabilitas didasarkan pada jawaban terbanyak yang dipilih responden dari empat pilihan yang ada pada kuesioner yang telah divalidasi dengan hasil wawancara. Namun, level 2-5 kapabilitas ini baru dapat terpenuhi apabila seluruh level kapabilitas sebelumnya telah mencapai rating fully achieved.

Ketercapaian atribut kapabilitas level 1 berdasarkan data yang telah didapat yaitu:

4.3.1.1 Dari 19 pertanyaan level 1 EDM03 (Ensure Risk Optimisation) yang sudah divalidasi, terdapat 2 jawaban "Ya" dan 17 jawaban "Tidak". Sehingga persentase ketercapaian level 1 optimasi risiko $\frac{2}{19} \times 100 \%=10,5 \%$ dengan rating not achieved.

4.3.1.2 Dari 34 pertanyaan level 1 APO12 (Manage Risk) yang sudah divalidasi, terdapat 4 jawaban "Ya" dan 30 jawaban "Tidak". Sehingga persentase ketercapaian level 1 manajemen risiko $\frac{4}{34} \times 100 \%=11,7 \%$ dengan rating not achieved.

Dari perhitungan tersebut diketahui bahwa $10,5 \%$ base practices dan work products telah dipenuhi dalam proses optimasi risiko, dan $11,7 \%$ dalam proses manajemen risiko. Dengan demikian berdasarkan skala rating pada COBIT 5 maka ketercapaian level 1 pada proses optimasi risiko dan manajemen risiko pada sistem informasi koperasi syariah KSPPS XYZ ialah partially achieved. Pencapaian ini menunjukkan bahwa tidak semua base practices dilaksanakan dan tidak semua work products digunakan dan dihasilkan pada proses.

Hasil pengukuran kapabilitas proses optimasi risiko dan manajemen risiko secara keseluruhan didapatkan dari perhitungan berikut:

1. Ketercapaian atribut kapabilitas level 2-5 EDM03 (Ensure Risk Optimisation) berdasarkan data yang telah didapat yaitu:

a. PA2.1 Performance management, terdapat 4 jawaban not achieved, 1 jawaban partially achieved dan 1 jawaban fully achieved, sehingga perhitungannya:

$$
\begin{gathered}
\mathrm{NR}=\frac{(4 * 0+1 * 1+0 * 2+1 * 3)}{6} \\
\mathrm{NR}=\frac{4}{6}
\end{gathered}
$$

$\mathrm{NR}=0,67$ dengan rating partially achieved

b. PA2.2 Work product management, terdapat 4 jawaban not achieved, sehingga perhitungannya:

$\mathrm{NR}=0$ dengan rating not achieved

$$
\begin{gathered}
\mathrm{NR}=\frac{(4 * 0+0 * 1+0 * 2+0 * 3)}{4} \\
\mathrm{NR}=\frac{0}{4}
\end{gathered}
$$

c. PA3.1 Process definition, terdapat 5 jawaban not achieved, sehingga perhitungannya:

$\mathrm{NR}=0$ dengan rating not achieved

$$
\mathrm{NR}=\frac{(5 * 0+0 * 1+0 * 2+0 * 3)}{5}
$$

d. PA3.2 Process deployment, terdapat 6 jawaban not achieved, sehingga perhitungannya:

$\mathrm{NR}=0$ dengan rating not achieved

$$
\begin{gathered}
\mathrm{NR}=\frac{(6 * 0+0 * 1+0 * 2+0 * 3)}{6} \\
\mathrm{NR}=\frac{0}{6}
\end{gathered}
$$

e. PA4.1 Process measurement, terdapat 6 jawaban not achieved, sehingga perhitungannya:

$\mathrm{NR}=0$ dengan rating not achieved

$$
\begin{gathered}
\mathrm{NR}=\frac{(6 * 0+0 * 1+0 * 2+0 * 3)}{6} \\
\mathrm{NR}=\frac{0}{6}
\end{gathered}
$$


f. PA4.2 Process control, terdapat 5 jawaban not achieved, sehingga perhitungannya:

$\mathrm{NR}=0$ dengan rating not achieved

$$
\begin{gathered}
\mathrm{NR}=\frac{(5 * 0+0 * 1+0 * 2+0 * 3)}{5} \\
\mathrm{NR}=\frac{0}{5}
\end{gathered}
$$

g. PA5.1 Process innovation, terdapat 5 jawaban not achieved, sehingga perhitungannya:

$\mathrm{NR}=0$ dengan rating not achieved

$$
\mathrm{NR}=\frac{(5 * 0+0 * 1+0 * 2+0 * 3)}{5}
$$

h. PA5.2 Continous optimization, terdapat 3 jawaban not achieved, sehingga perhitungannya:

$\mathrm{NR}=0$ dengan rating not achieved

$$
\mathrm{NR}=\frac{(3 * 0+0 * 1+0 * 2+0 * 3)}{5}
$$

2. Ketercapaian atribut kapabilitas level 2-5 APO12 (Manage Risk) berdasarkan data yang telah didapat yaitu:

a. PA2.1 Performance management, terdapat 5 jawaban partially achieved dan 1 jawaban fully achieved, sehingga perhitungannya:

$$
\begin{gathered}
\mathrm{NR}=\frac{(0 * 0+5 * 1+0 * 2+1 * 3)}{6} \\
\mathrm{NR}=\frac{8}{6}
\end{gathered}
$$

$\mathrm{NR}=1,33$ dengan rating partially achieved

b. PA2.2 Work product management, terdapat 3 jawaban not achieved dan 1 jawaban partially achieved, sehingga perhitungannya:

$\mathrm{NR}=0,25$ dengan rating not achieved

$$
\begin{gathered}
\mathrm{NR}=\frac{(3 * 0+1 * 1+0 * 2+0 * 3)}{4} \\
\mathrm{NR}=\frac{1}{4}
\end{gathered}
$$

c. PA3.1 Process definition, terdapat 4 jawaban not achieved dan 1 jawaban largelly achieved, sehingga perhitungannya:

$\mathrm{NR}=0,4$ dengan rating not achieved

$$
\begin{gathered}
\mathrm{NR}=\frac{(4 * 0+0 * 1+1 * 2+0 * 3)}{5} \\
\mathrm{NR}=\frac{2}{5}
\end{gathered}
$$

d. PA3.2 Process deployment, terdapat 5 jawaban not achieved dan 1 jawaban partially achieved, sehingga perhitungannya:

$\mathrm{NR}=0,16$ dengan rating not achieved

$$
\begin{gathered}
\mathrm{NR}=\frac{(5 * 0+1 * 1+0 * 2+0 * 3)}{\mathrm{NR}=\frac{1}{6}} \\
\text { (5) }
\end{gathered}
$$

e. PA4.1 Process measurement, terdapat 6 jawaban not achieved, sehingga perhitungannya:

$$
\mathrm{NR}=\frac{(6 * 0+0 * 1+0 * 2+0 * 3)}{6}
$$


$\mathrm{NR}=0$ dengan rating not achieved

f. PA4.2 Process control, terdapat 5 jawaban not achieved, sehingga perhitungannya:

$\mathrm{NR}=0$ dengan rating not achieved

$$
\begin{gathered}
\mathrm{NR}=\frac{(5 * 0+0 * 1+0 * 2+0 * 3)}{5} \\
\mathrm{NR}=\frac{0}{5}
\end{gathered}
$$

g. PA5.1 Process innovation, terdapat 5 jawaban not achieved, sehingga perhitungannya:

$\mathrm{NR}=0$ dengan rating not achieved

$$
\begin{gathered}
\mathrm{NR}=\frac{(5 * 0+0 * 1+0 * 2+0 * 3)}{5} \\
\mathrm{NR}=\frac{0}{5}
\end{gathered}
$$

h. PA5.2 Continous optimization, terdapat 3 jawaban not achieved, sehingga perhitungannya:

$\mathrm{NR}=0$ dengan rating not achieved

$$
\begin{gathered}
\mathrm{NR}=\frac{(3 * 0+0 * 1+0 * 2+0 * 3)}{5} \\
\mathrm{NR}=\frac{0}{3}
\end{gathered}
$$

Pemetaan hasil rekapitulasi data terhadap pencapaian atribut level seperti pada Tabel 4Tabel 4 dan Tabel 5.

Tabel 4 Pemetaan Hasil Rekapitulasi Data terhadap Pencapaian Atribut Proses EDM03 (Ensure Risk Optimisation)

\begin{tabular}{cll}
\hline \multicolumn{1}{c}{ Tingkat } & \multicolumn{1}{c}{ Atribut } & \multicolumn{1}{c}{ Rating } \\
\hline 1-Performed & PA1.1-Process performance & Not achieved \\
\hline \multirow{2}{*}{ 2-Managed } & PA2.1-Performance management & Partially achieved \\
\cline { 2 - 3 } & PA2.2-Work product management & Not achieved \\
\hline \multirow{2}{*}{ 3-Established } & PA3.1-Process definition & Not achieved \\
\cline { 2 - 3 } & PA3.2-Process deployment & Not achieved \\
\hline \multirow{2}{*}{ 4-Predictable } & PA4.1-Process measurement & Not achieved \\
\cline { 2 - 3 } & PA4.2-Process control & Not achieved \\
\hline \multirow{2}{*}{ 5-Optimizing } & PA5.1-Process innovation & Not achieved \\
\cline { 2 - 3 } & PA5.2-Continous optimization & Not achieved
\end{tabular}

Tabel 5 Pemetaan Hasil Rekapitulasi Data terhadap Pencapaian Atribut Proses APO12 (Manage Risk)

\begin{tabular}{cll}
\hline \multicolumn{1}{c}{ Tingkat } & \multicolumn{1}{c}{ Atribut } & \multicolumn{1}{c}{ Rating } \\
\hline 1-Performed & PA1.1-Process performance & Not achieved \\
\hline \multirow{2}{*}{ 2-Managed } & PA2.1-Performance management & $\begin{array}{l}\text { Partially } \\
\text { achieved }\end{array}$ \\
\cline { 2 - 3 } & PA2.2-Work product management & Not achieved \\
\hline \multirow{2}{*}{ 3-Established } & PA3.1-Process definition & Not achieved \\
\cline { 2 - 3 } & PA3.2-Process deployment & Not achieved \\
\hline 4-Predictable & PA4.1-Process measurement & Not achieved \\
\hline
\end{tabular}




\begin{tabular}{lll}
\hline & PA4.2 - Process control & Not achieved \\
\hline \multirow{2}{*}{ 5-Optimizing } & PA5.1 - Process innovation & Not achieved \\
\cline { 2 - 3 } & PA5.2 - Continous optimization & Not achieved \\
\hline
\end{tabular}

Dari Tabel 4 dan Tabel 5, dapat diketahui bahwa untuk atribut level 1 proses optimasi risiko dan manajemen risiko mencapai rating partially achieved. Berdasarkan COBIT 5, proses baru dianggap mampu mencapai kapabilitas level berikutnya apabila kapabilitas level sebelumnya telah mencapai rating fully achieved. Karena level 1 pada proses optimasi risiko dan manajemen risiko belum mencapai fully achieved maka dapat disimpulkan bahwa kapabilitas proses optimasi risiko dan manajemen risiko sistem informasi koperasi syariah KSPPS XYZ baru mencapai level 0 yang artinya KSPPS XYZ gagal mencapai tujuan optimasi risiko dan manajemen risiko.

\subsection{Analisis Data}

Dari hasil wawancara dapat diketahui bahwa KSPPS XYZ belum menerapkan optimasi risiko tapi dalam proses manajemen risiko TI sudah sebagian diterapkan. Hal tersebut yang terbukti dengan adanya pengelolaan terhadap risiko apabila terjadi sebuah insiden meskipun hanya berdasarkan pengalaman dan terdapat banyak kekurangan, seperti belum adanya beberapa permasalahan berikut ini.

1. Kurangnya pendefinisian, pendokumentasian dan pengendalian hasil pengerjaan proses optimasi risiko maupun manajemen risiko sistem informasi koperasi syariah KSPPS XYZ. Selama ini hasil pengerjaan proses optimasi risiko dan manajemen risiko sistem informasi koperasi syariah KSPPS XYZ belum memiliki struktur yang jelas dan kurang rinci. Hasil pengerjaan proses optimasi risiko maupun manajemen risiko belum terdokumentasi dengan baik. Work products perlu ditentukan secara jelas agar pelaksanaan proses dapat disesuaikan dengan tujuan. Selain itu, work products yang telah terstruktur memudahkan KSPPS XYZ untuk melakukan penilaian kinerja terhadap proses yang sudah dijalankan sehingga dapat membuat rencana perbaikan agar pelaksanaan proses di masa depan menjadi lebih baik.

2. Standar/kebijakan/panduan pelaksanaan optimasi risiko dan manajemen risiko pada KSPPS XYZ belum diatur.

3. Implementasi proses proses optimasi risiko dan manajemen risiko pada KSPPS XYZ masih terjadi berbagai kesalahan. Pelaksanaan proses didasarkan atas intuisi dan pengalaman individu sehari-hari.

4. Belum adanya analisis dan evaluasi terhadap hasil pengelolaan dan hasil penilaian kinerja proses untuk perbaikan pengelolaan proses ke depannya.

Untuk mencapai target kapabilitas 3, KSPPS XYZ perlu melakukan beberapa perbaikan dalam pengimplementasian proses optimasi risiko dan manajemen risiko. Rekomendasi perbaikan proses dilakukan dalam beberapa tahap. Tahap pertama adalah meningkatkan kapabilitas proses dari level 0 ke level 1. Perbaikan tersebut harus dimulai dari level 1 dan baru boleh dilanjutkan ke level berikutnya apabila keseluruhan langkah perbaikan pada level tersebut telah dipenuhi dan dilakukan secara konsisten. Berikut ini merupakan rekomendasi perbaikan yang dapat dilakukan KSPPS XYZ.

1) Pencapaian Kapabilitas Level 1

Untuk mencapai level 1 sepenuhnya dengan rating fully achieved, KSPPS XYZ perlu memenuhi work products yang belum ada, yaitu sebagai berikut.

4.4.1.1.1 Work products EDM03 yang perlu dipenuhi:

1) Prinsip manajemen risiko perusahaan

2) Permasalahan dan faktor risiko yang muncul.

3) Profil manajemen risiko perusahaan dan rencana mitigasi.

4) Analisis risiko dan laporan profil risiko untuk para pemangku kepentingan.

5) Hasil analisis risiko.

6) Tinjauan hasil penilaian risiko pihak ketiga.

7) Peluang untuk penerimaan risiko yang lebih besar.

8) Panduan risk appetite.

9) Tingkat toleransi risiko yang disetujui.

10) Evaluasi kegiatan manajemen risiko. 
11) Kebijakan manajemen risiko.

12) Tujuan utama organisasi untuk dimonitor sebagai manajemen risiko.

13) Proses yang disetujui untuk mengukur manajemen risiko.

14) Tindakan remedial untuk mengatasi penyimpangan manajemen risiko.

15) Masalah manajemen risiko untuk pemangku kepentingan.

4.5 Work products APO12 yang perlu dipenuhi:

1) Evaluasi kegiatan manajemen risiko.

2) Kebijakan manajemen risiko.

3) Tujuan utama organisasi untuk dimonitor manajemen risiko.

4) Proses yang disetujui untuk mengukur manajemen risiko.

5) Laporan insiden status dan tren.

6) Peringatan ancaman.

7) Analisis dampak bisnis.

8) Evaluasi potensi ancaman.

9) Panduan risk appetite.

10) Tingkat toleransi risiko yang disetujui.

11) Identifikasi risiko dari supplier.

12) Evaluasi potensi ancaman.

13) Tindakan remedial untuk mengatasi penyimpangan manajemen risiko.

14) Data pada lingkungan operasi yang berkaitan dengan risiko.

15) Data tentang kejadian risiko dan faktor yang berkontribusi.

16) Permasalahan dan faktor risiko yang muncul.

17) Lingkup upaya analisis risiko.

18) Skenario risiko TI.

19) Hasil analisis risiko.

20) Dokumentasi skenario risiko dari lini bisnis dan fungsi.

21) Agregat profil risiko termasuk status tindakan manajemen risiko.

22) Analisis risiko dan laporan profil risiko untuk para pemangku kepentingan.

23) Tinjauan hasil penilaian risiko pihak ketiga.

24) Peluang untuk menerima risiko yang lebih besar.

25) Proposal proyek untuk mengurangi risiko.

26) Rencana respon insiden terkait risiko.

27) Komunikasi dampak risiko.

28) Akar penyebab risiko yang terkait.

Seluruh work products ini harus didokumentasikan dan dikomunkasikan dengan baik serta disesuaikan dengan proses lain yang berkaitan dengan proses optimasi risiko dan manajemen risiko. Selain itu seluruh work product harus selalu diperbarui sesuai perubahan yang terjadi pada KSPPS XYZ.

2) Pencapaian Kapabilitas Level 2

Berikut hal-hal yang dapat dilakukan KSPPS XYZ untuk melakukan perbaikan proses optimasi risiko dan manajemen risiko.

a. Mengidentifikasi tujuan dan kinerja proses dan dituangkan dalam sebuah dokumen.

b. Merencanakan, mengatur dan mengawasi kinerja proses agar dapat mencapai tujuan yang telah ditetapkan, dibuktikan dalam laporan rencana proses, catatan kinerja proses dan catatan kualitas.

c. Menentukan tanggung jawab dan otoritas dalam pelaksanaan proses.

d. Mengidentifikasi dan menyediakan sumber daya untuk melaksanakan proses berdasarkan rencana yang telah dibuat.

e. Mengelola pihak-pihak yang terlibat.

f. Mendefinisikan, mengelola dan mengevaluasi work product

3) Pencapaian Kapabilitas Level 3

Berikut ini merupakan rekomendasi perbaikan yang dapat dilakukan KSPPS XYZ.

a. Mendefinisikan standar proses termasuk urutan dan interaksi antar proses, peran dan kompetensi untuk melaksanakan proses, infrastruktur dan lingkungan kerja dan metode yang sesuai untuk mengawasi proses, yang kemudian dituangkan dalam dokumen kebijakan dan standar. 
b. Menetapkan dan mengkomunikasikan peran dan tanggung jawab dan wewenang untuk melaksanakan proses.

c. Melakukan sosialisasi terhadap standar dan prosedur pada semua lingkup organisasi dan pegawai serta melakukan rencana pelatihan formal bagi personil TI untuk meningkatkan kompetensi.

d. Menyediakan sumber daya dan informasi serta infrastruktur untuk mendukung kinerja proses.

e. Melakukan audit internal dan review dengan hasil berupa catatan kinerja proses untuk disampaikan ke pihak manajemen guna megetahui efektivitas.

\section{Kesimpulan}

Kesimpulan yang dapat diambil dari Kesimpulan yang dapat diambil dari pengerjaan Tugas Akhir ini ialah sebagai berikut.

1. Berdasarkan standar pada COBIT 5, proses optimasi risiko dan manajemen risiko sistem informasi syariah KSPPS XYZ berada pada level kapabilitas 0 yang artinya KSPPS XYZ gagal mencapai tujuan optimasi risiko dan manajemen risiko.

2. Level kapabilitas proses optimasi risiko dan manajemen risiko yang seharusnya dicapai oleh sistem informasi koperasi syariah KSPPS XYZ ialah level 3 (established) dengan rating ketercapaian atribut largely achieved. Level ini didapatkan dari hasil wawancara dengan staff IT, manajer SDI dan maal serta manajer operasional.

3. Untuk meningkatkan kapabilitas optimasi risiko dan manajemen risiko di KSPPS XYZ, maka diberikan rekomendasi perbaikan sebagai langkah untuk memperbaiki proses optimasi risiko dan manajemen risiko agar dapat mencapai tingkat kapabilitas yang ditargetkan yaitu level 3 (established). Rekomendasi perbaikan disusun berdasarkan kerangka kerja COBIT 5 dan dilakukan secara bertahap mulai dari peningkatan level terendah hingga mencapai level target yang diinginkan. Implementasi rekomendasi perbaikan harus dilakukan secara konsisten mulai dari level 1 hingga ketercapaian atribut pada level 1 sampai 2 mencapai rating fully achieved dan ketercapaian atribut level 3 mencapai rating largely achieved..

\section{Daftar Pustaka}

[1] Astuti, H. M., Muqtadiroh, F. A., Wahyu, E., \& Darmaningrat, T. (2018). ScienceDirect Risks Assessment of Information Technology Processes Based on COBIT 5 Framework : A Case Study of ITS Service Desk. Procedia Computer Science, 124, 569-576. https://doi.org/10.1016/j.procs.2017.12.191.

[2] Gibson, D. (2014). Managing Risk in Information Systems (1st ed.). Canada: Jones \& Bartlett Learning.

[3] Andry, J. F. (2016). Audit of IT Governance Based on COBIT 5 Assessments : A Case Study. TEKNOSI, 02(02), 27-34.

[4] ISACA. (2012). A Business Framework for the Governance and Management of Enterprise IT. USA. Retrieved from www.isaca.org.

[5] Lestari, R. (2014). Audit Sistem Informasi Bagian Sumber Daya Manusia Pada PT Bando Indonesia Dengan Pendekatan COBIT 5. Universitas Esa Unggul. Retrieved from https://digilib.esaunggul.ac.id

[6] Siburian, N. W. (2015). Pengukuran Tingkat Kapabilitas Tata Kelola Teknologi Informasi Menggunakan Kerangka Kerja COBIT 5: Studi Kasus Direktorat Metrologi Kementrian Perdagangan. Universitas Indonesia.

[7] Yulhendri. (2017). IT Governance Assesment Menggunakan COBIT 5 di Bank XYZ. Universitas Esa Unggul. Retrieved from https://digilib.esaunggul.ac.id.

[8] Arief, M. H. (2018). Evaluasi Manajemen Risiko Teknologi Informasi Menggunakan Kerangka Kerja COBIT 5 ( Studi Kasus Pada Perum Jasa Tirta I Malang ). Jurnal Pengembangan Teknologi Informasi Dan Ilmu Komputer, 2(1).

[9] ISACA. (2012). Enabling Processes. USA. Retrieved from www.isaca.org

[10] Indonesia. Undang-Undang Nomor 25 Tahun 1992 Tentang Perkoperasian, Pub. L. No. 25, 1 (1992). Indonesia. 
[11] Sekretariat, K. K. dan U. (n.d.). Kementrian Koperasi dan Usaha Kecil dan Menengah Republik Indonesia. Retrieved July 22, 2019, from http://www.depkop.go.id/

[12] Setyaningrum, N. D., \& Kusyanti, A. (2018). Evaluasi Manajemen Risiko Teknologi Informasi Menggunakan Framework COBIT 5 ( Studi Kasus: PT . Kimia Farma ( Persero ) Tbk - Plant Watudakon ). Jurnal Pengembangan Teknologi Informasi Dan Ilmu Komputer, 2(1), 143-152.

[13] Amanah, P. H. (2014). Pengukuran Kapabilitas Proses Pengelolaan Permintaan dan Insiden Layanan Teknologi Informasi dengan Framework COBIT 5 Studi kasus: PT. Pos Indonesia (Persero). Institut Teknologi Bandung.

[14] Andry, J. F., \& Christianto, K. (2018). Audit Menggunakan COBIT 4.1 dan COBIT 5 dengan Case Study (1st ed., p. 388). Yogyakarta: Teknosain. 